\title{
Do More Signals Mean Higher Profits?
}

\author{
$\underline{\text { Alexandra Klados }}$ \\ ${ }^{a}$ School of Economics and Finance, Curtin University, GPO Box U1987, Perth, 6845, Western Australia \\ Email:a.klados@curtin.edu.au
}

\begin{abstract}
This paper examines the profitability of speculation trading by combining multiple technical indicators for entry requirements. The technical indicators considered in this paper include simple moving average and volume traded over different time horizons. Three different indicators were combined in thirtytwo ways and the portfolios were followed for twelve years. Various methods of combining technical indicators will also be considered. The sample begins in January 2007 and it is chosen for purposes of analysing the impact of global financial crisis on trading. The performance of the different trading strategies will be evaluated by the annual risk-adjusted return of a portfolio. Trading costs are considered inconsequential in this case, given the proliferation of online brokerage companies, and will therefore be ignored.

The results contain evidence to support that forecast combination could be beneficial when applying to trading environment. More generally, this paper provides evidence to support that the advantage of forecast combination goes beyond improving mean-squared errors, it could also improve performance based on realistic objective functions.
\end{abstract}

Keywords: $\quad$ Technical Trading, Combination, Stop-loss 


\section{INTRODUCTION}

The objective of this paper is to examine if using multiple technical indicators can lead to above average returns.

The use of technical trading rules to try to outperform the market on a risk-adjusted basis has been around for decades with investors using a variety of technical indicators to check for buy/sell signals. One of the most comprehensive studies was done by Brock, Lakonishok, and LeBaron (1992). They applied 26 technical indicators to the Dow Jones Industrial Average (DJIA) and found that all 26 indicators outperformed the benchmark, of holding cash, during the ninety years ending with 1986.

A further study by (Sullivan, Timmermann, and White 1999)) utilised not just the 26 indicators as in Brock et al. but a "full universe of trading rules" to avoid data snooping. Sullivan et al (1999) in fact tested a total of 7,846 trading rules over the 100 year period ending 1996. In addition to looking at their own "full universe of trading rules" (Sullivan, Timmermann, and White 1999), they also checked if the technical trading rule found by Brock et al to be the best performer during the 90 years of the original study was still found to be the best indicator when trying to predict the future movements of the DJIA. Sullivan et al (1999) found that this was not the case.

It is interesting to note that when comparing the technical trading rules considered to be the "best" by both the Brock et al (1992) and the Sullivan et al (1999) studies the results were not consistent. This is understandable as the number of trading rules tested by Sullivan et al is considerably larger. One would expect that for the whole period, or any given sub period, the two studies would find different technical indicators to be the best. For example, for the sub period 1939-1962 Brock et al that the best performing technical trading rule was the 50-day moving average, while Sullivan et al found that the best performer was the 2-day on-balance volume.

In the Australian market Pavlov and Hurn (2012) tested the use of multiple moving average rules, where the cross point of two different moving averages where used as an indicator for portfolio selection. It can be seen that there is mixed results in the literature on whether technical trading rules provide any economic value, or the superior risk-adjusted returns are a result of data-snooping. Therefore rather than simply looking at more individual trading rules, this paper looks at whether or not combining multiple trading rules would achieve higher risk adjusted returns instead, and whether or not the combination of these rules would also outperform the benchmark.

\section{METHODOLOTY}

A portfolio of nineteen stocks was created to test the three basic technical rules analysed. The stocks in the portfolio were chosen based on their liquidity and volatility. The stocks' liquidity was assessed based on the average number of shares traded per day over a three month period, and this must be greater than 500,000 shares traded per day.

Volatility was assessed based on the stocks 52-week trading range compared to the median price of the year. In other words, the annual high and low were used to find the annual trading range of the stock, this trading range must be greater and fifty percent of the median price. For example if the highest and lowest price of the year are $\$ 92.00$ and $\$ 47.50$ respectively with the median price for the year $\$ 62.00$, the 52 -week range is 44.50 and 50 percent of the median price is 31 , therefore the stock could be chosen for the portfolio.

Three technical indicators were chosen; a simple daily moving average (dMA), on-balance volume (OBV) and an intra-day price (1030Price).

Moving averages are arguable the simplest and probably the most common of the trading rules used today. Gartley (1935) discussed that the "penetration of a moving average is regarded as a ... signal." (Gartley 1935) The daily moving average is calculated on the closing price of each trading day as follows:

$$
d M A_{P, t}(N)=\frac{1}{N} \sum_{j=N-1}^{0} V_{t-j}
$$

and the signal for entry is

$$
V_{t-1}>d M A_{t-1}>V_{t-2}
$$


On-Balance volume (OBV) was made popular by Granvillle (1976). OBV keeps a running total of the volume by adding the day's volume when the return was positive and subtracting the volume when the day's return was negative.

$$
O B V_{t}=O B V_{t-1}+ \begin{cases}\text { volume } & \text { if close } \text { close }_{t-1} \\ 0 & \text { if close } \text { close }_{t-1} \\ - \text { volume }_{\text {if }} \text { close }_{t}<\text { close }_{t-1}\end{cases}
$$

A moving average can then be imposed on the OBV to give a trading "signal" just as with the dMA (1) and (2).

The last technical indicator is the 1030Price. The signal for entry would be if the 1030Price of trading day is above than the dMA. However, unlike the dMA and OBV, which are compared to their own moving averages, the 1030Price is compared to the daily moving average calculated on the closing price.

These rules were then individually applied to nineteen stocks in order to obtain entry (buy/sell) signals. These individual signals were then combined in eight possible ways.

\begin{tabular}{|c|ccc} 
& dMA & OBV & 1030Price \\
\hline C1 & $\mathrm{X}$ & & \\
C2 & & $\mathrm{X}$ & $\mathrm{X}$ \\
C3 & & & \\
C4 & $\mathrm{X}$ & $\mathrm{X}$ & $\mathrm{X}$ \\
C5 & $\mathrm{X}$ & & $\mathrm{X}$ \\
C6 & & $\mathrm{X}$ & $\mathrm{X}$ \\
\hline C7 & & $\mathrm{X}$ & \\
\hline C8 & $\mathrm{X}$ & & \\
\hline
\end{tabular}

As can be seen in table $1 \mathrm{C} 1$ to $\mathrm{C} 3$ are the "individual" rules and the remainder a combination. For example, $\mathrm{C} 4$ indicated that a position would only be taken if both $\mathrm{dMA}$ and OBV where triggered. When no trade was initiated a cash position was held, where the 90 day Treasury was used as the cash rate. C7 can be considered the cash benchmark, as this would be the position taken when none of the indicators were considered, so no trade was made. An alternate benchmark was the buy/hold for the SP500 over the period of twelve years under consideration.

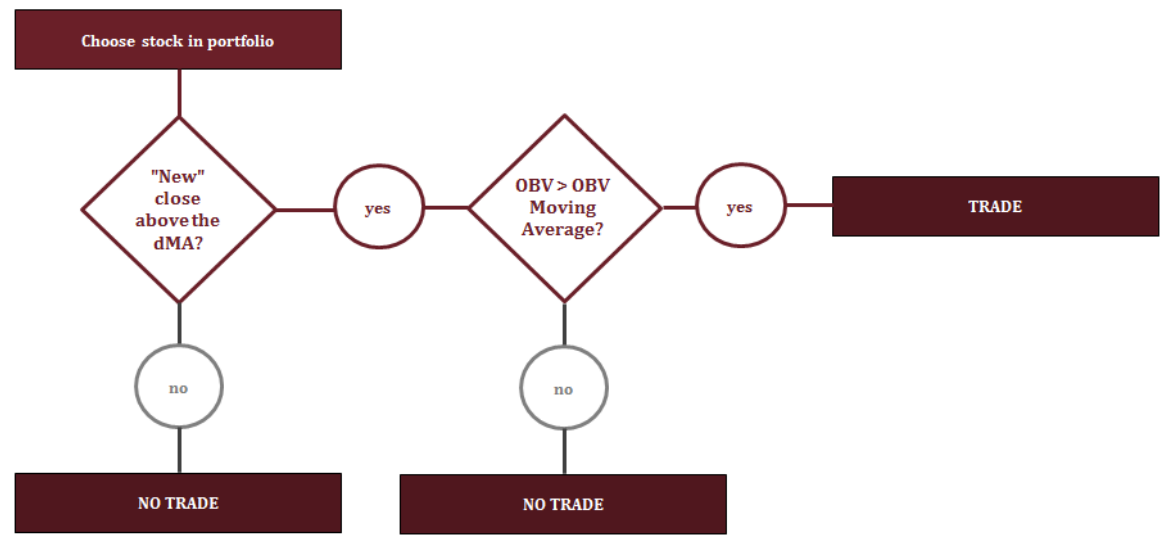

Figure 1. Entry process for $\mathrm{C} 4$

The combinations ( $\mathrm{C} 1$ through $\mathrm{C} 8$ ) were also divided into four subgroups determined by exit requirements. These were a ten percent return without a stop-loss (W), and a ten percent return with a three percent stoploss (X). A thirty-five day holding period without a stop-loss (Y) and last, a thirty-five day holding period with three percent stop-loss (Z). Therefore C6Z is combination 6 from table one (using OBV and 1030Price) with a thirty-five day holding period and three percent stop-loss. 
A stop-loss is an automated exit trigger which can be setup during the initiation of the trade. When a stoploss was used it was set to a three percent loss. This means that if the cumulative loss on any given trade reached three percent, the trade was automatically exited. Trading with only a profit target (without a stoploss), means that you would be trading without a "safety-net" and the potential loss can be significant, as can be seen in $\mathrm{C} 4 \mathrm{~W}$, where the annual risk-adjusted loss was $172.81 \%$ !

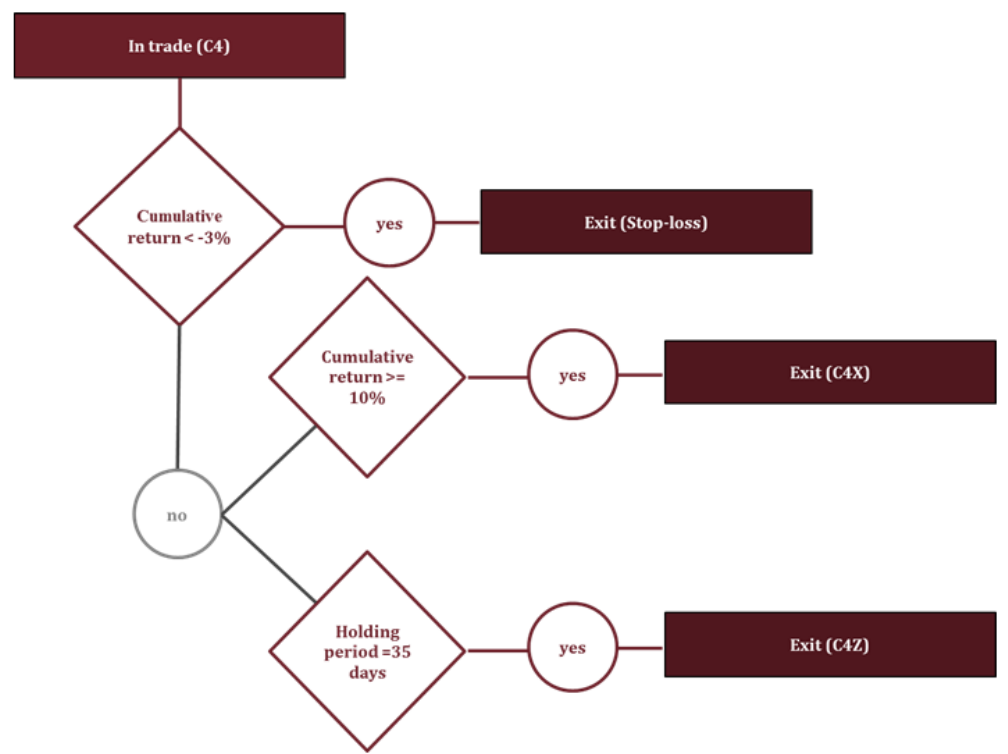

Figure 2. Exit process for $\mathrm{C} 4 \mathrm{X}$ and/or $\mathrm{C} 4 \mathrm{Z}$

Daily closing and 1030Price as well as volume were obtained from Bloomberg and Reuters Tick History for the period starting December 2000 through to December 2012 with the first potential trade on the $3^{\text {rd }}$ of January 2001

Excluding the general market closure over September of 2001, there were few non-trading days for the stocks in the portfolio. Non trading days were therefore given a return of zero per cent, i.e.: the stock was valued at the previous day's closing price and volume. As there were only eight trading halts over the twelve years under analysis, this should have negligible effect on portfolio returns.

Two performance measurement tools were used to evaluate the success of each of the thirty-two combination of trading rules; the Sharpe ratio and Jensen's alpha. The Sharpe ratio is a relative reward-to-risk measure where the excess portfolio return is divided by its standard deviation

$$
S=\frac{r_{p f}-r_{r f}}{\sigma_{p f}}
$$

and Jensen's alpha gives an absolute measure of the risk-adjusted performance by providing the intercept in a regression of the excess returns of the portfolio to the market, in this case the SP500.

$$
\alpha_{p f}=r_{p f}-\left[r f-b_{p f}(r m-r f)\right]
$$

\section{RESULTS}

As can be seen in figure 3, exit strategies $\mathrm{X}$ and $\mathrm{Z}$ performed significantly better than $\mathrm{W}$ and $\mathrm{Y}$, indicating that trading with a stop-loss is preferable to trading without one. This would also help with the preservation of capital in the event that the trade went against indicators.

When ranking the portfolios according to their Sharpe ratio or Jensen's alpha, there is no difference in the order of the first 5 portfolios. The highest risk-adjusted return was achieved by combining the OBV and the 
1030 Price. Using both the OBV and the 1030 Price provides us with an additional $8.6543 \%$ risk-adjusted return (increase in the Sharpe ratio) above that given simply by using the OBV individually.



Figure 3. Sharpe Ratios 2001-2012

The two benchmark portfolios C7 and the buy/hold in the SP500 came in at $20^{\text {th }}$ and $27^{\text {th }}$ when ranked according to the Sharpe ratio; however it does move to $21^{\text {st }}$ and $20^{\text {th }}$ respectively when looking at Jensen's alpha.

When looking at the top ten ranked portfolios (either by Sharpe or Jensen), six of these portfolios used a combination of triggers for entry requirements. Out of these, five used OBV and eight of the top ten used the 1030 Price as a trigger. It is interesting to note that combinations $\mathrm{C} 3 \mathrm{Z}$ and $\mathrm{C} 3 \mathrm{X}$, where the entry is determined solely by the 1030Price and the exit is a thirty-five day holding period and a ten percent return respectively came in fifth and sixth. This might indicate that while the 1030Price is important, it is more of a secondary trigger, a reinforcement of market direction rather than the primary indicator of market direction.

When looking at which exit strategies performed best all of the best performing portfolios had a stop loss. In fact the highest ranked portfolio without a stop-loss (C3Y) came in twelfth. The worst performing portfolios were all portfolios trading without a stop-loss, indicating that trading without a stop-loss can be extremely dangerous.

When comparing the thirty-five day holding-period and the ten percent return requirements, the top three portfolios all had a thirty-five day holding period requirement (combinations ending with a " $Z$ ") and out of the top ten only four where combinations where the return was determined by a percentage return, in our case ten percent return (combinations ending with an "X").

\section{CONCLUSION}

While it can be said that $\mathrm{C} 6 \mathrm{Z}$ was the best performing portfolio, it would not be correct to assume that combining the $\mathrm{OBV}$ and the 1030Price will always yield the best results. Looking at the four possible version of C6 one can see that they rank "all over the place" with C6X as fourth, C6Y as fourteenth and C6W as twenty-eighth! This shows that deciding when and why to exit is just as important in determining the success of the trade as deciding when and why to enter a trade.

A further study could look at how changing the exit requirements would change the information provided by the three technical indicators. At the moment the OBV and 1030Price provide the best information for a portfolio if you want to stay in the trade for thirty-five days and trade with a stop-loss. The addition of the 1030 Price adds approximately $8.5 \%$ in risk adjusted return. An interesting extension to this study would to see if lengthening the holding period, for example to 90 or 180 days change the benefit derived using both the OBV and the 1030Price or not. 
Annualized 2001 -2012

\begin{tabular}{|c|c|c|c|c|c|}
\hline & & Return & St. dev & Sharpe & Jensen \\
\hline 1 & C6Z & $74.6601 \%$ & $16.7927 \%$ & $434.1583 \%$ & $72.5286 \%$ \\
\hline 2 & $\mathrm{C} 2 \mathrm{Z}$ & $62.6027 \%$ & $14.3005 \%$ & $425.5041 \%$ & $60.6999 \%$ \\
\hline 3 & $\mathrm{C} 1 \mathrm{Z}$ & $60.3864 \%$ & $16.9923 \%$ & $345.0572 \%$ & $58.2032 \%$ \\
\hline 4 & C6X & $46.8070 \%$ & $13.0834 \%$ & $344.3584 \%$ & $44.8415 \%$ \\
\hline 5 & $\mathrm{C} 3 \mathrm{Z}$ & $43.9971 \%$ & $18.3522 \%$ & $230.1833 \%$ & $41.8008 \%$ \\
\hline 6 & $\mathrm{C} 3 \mathrm{X}$ & $20.4916 \%$ & $8.4984 \%$ & $220.4911 \%$ & $18.6881 \%$ \\
\hline 7 & $\mathrm{C} 8 \mathrm{Z}$ & $38.8065 \%$ & $17.8347 \%$ & $207.7584 \%$ & $36.6064 \%$ \\
\hline 8 & $\mathrm{C} 5 \mathrm{Z}$ & $38.1170 \%$ & $18.2283 \%$ & $199.4902 \%$ & $35.9108 \%$ \\
\hline 9 & $\mathrm{C} 8 \mathrm{X}$ & $16.4766 \%$ & $8.5211 \%$ & $172.7850 \%$ & $14.6559 \%$ \\
\hline 10 & $\mathrm{C} 5 \mathrm{X}$ & $16.3302 \%$ & $8.6669 \%$ & $168.1891 \%$ & $14.5146 \%$ \\
\hline 11 & $\mathrm{C} 4 \mathrm{Z}$ & $29.9345 \%$ & $18.0747 \%$ & $155.9149 \%$ & $27.7064 \%$ \\
\hline 12 & $\mathrm{C} 3 \mathrm{Y}$ & $22.2246 \%$ & $18.7476 \%$ & $109.1940 \%$ & $20.0280 \%$ \\
\hline 13 & $\mathrm{C} 4 \mathrm{X}$ & $9.4697 \%$ & $8.5607 \%$ & $90.1369 \%$ & $7.6420 \%$ \\
\hline 14 & C6Y & $18.2089 \%$ & $19.4470 \%$ & $84.6174 \%$ & $15.9521 \%$ \\
\hline 15 & $\mathrm{C} 1 \mathrm{X}$ & $8.9329 \%$ & $8.7069 \%$ & $82.4576 \%$ & $7.1199 \%$ \\
\hline 16 & $\mathrm{C} 5 \mathrm{Y}$ & $10.3062 \%$ & $18.7293 \%$ & $45.6655 \%$ & $8.0972 \%$ \\
\hline 17 & $\mathrm{C} 8 \mathrm{Y}$ & $9.7141 \%$ & $18.1109 \%$ & $43.9556 \%$ & $7.5193 \%$ \\
\hline 18 & $\mathrm{C} 2 \mathrm{X}$ & $7.0610 \%$ & $13.3582 \%$ & $39.7328 \%$ & $5.1969 \%$ \\
\hline 19 & $\mathrm{C} 3 \mathrm{~W}$ & $3.1150 \%$ & $9.3714 \%$ & $14.5292 \%$ & $1.3219 \%$ \\
\hline 20 & $\mathrm{C} 7 \mathrm{~W}$ & $1.7534 \%$ & $0.1047 \%$ & $0.0000 \%$ & $-0.0001 \%$ \\
\hline 21 & $\mathrm{C} 7 \mathrm{X}$ & $1.7534 \%$ & $0.1047 \%$ & $0.0000 \%$ & $-0.0001 \%$ \\
\hline 22 & $\mathrm{C} 7 \mathrm{Y}$ & $1.7534 \%$ & $0.1047 \%$ & $0.0000 \%$ & $-0.0001 \%$ \\
\hline 23 & $\mathrm{C} 7 \mathrm{Z}$ & $1.7534 \%$ & $0.1047 \%$ & $0.0000 \%$ & $-0.0001 \%$ \\
\hline 24 & $\mathrm{C} 1 \mathrm{Y}$ & $1.4203 \%$ & $18.7250 \%$ & $-1.7786 \%$ & $-0.7872 \%$ \\
\hline 25 & $\mathrm{C} 4 \mathrm{Y}$ & $1.3000 \%$ & $18.5512 \%$ & $-2.4438 \%$ & $-0.9452 \%$ \\
\hline 26 & $\mathrm{C} 2 \mathrm{Y}$ & $1.0789 \%$ & $15.9813 \%$ & $-4.2207 \%$ & $-0.9113 \%$ \\
\hline 27 & SP500 & $0.1611 \%$ & $20.8790 \%$ & $-7.6264 \%$ & $0.0000 \%$ \\
\hline 28 & C6W & $-1.7540 \%$ & $16.0921 \%$ & $-21.7959 \%$ & $-3.8464 \%$ \\
\hline 29 & $\mathrm{C} 5 \mathrm{~W}$ & $-7.0544 \%$ & $9.7440 \%$ & $-90.3915 \%$ & $-8.8629 \%$ \\
\hline 30 & $\mathrm{C} 8 \mathrm{~W}$ & $-7.3377 \%$ & $9.6243 \%$ & $-94.4595 \%$ & $-9.1412 \%$ \\
\hline 31 & $\mathrm{C} 2 \mathrm{~W}$ & $-16.8720 \%$ & $14.2619 \%$ & $-130.5954 \%$ & $-18.7775 \%$ \\
\hline 32 & $\mathrm{C} 1 \mathrm{~W}$ & $-14.9136 \%$ & $9.7759 \%$ & $-170.4897 \%$ & $-16.7220 \%$ \\
\hline 33 & $\mathrm{C} 4 \mathrm{~W}$ & $-14.8982 \%$ & $9.6357 \%$ & $-172.8109 \%$ & $-16.7366 \%$ \\
\hline
\end{tabular}


A Klados, Do More Signals Mean Higher Profits?

\section{REFERENCES}

Brock, William, Josef Lakonishok, and Blake LeBaron. 1992. "Simple technical trading rules and the stochastic properties of stock returns." The Journal of Finance 47 (5): 1731-1764. doi:10.1111/j.15406261.1992.tb04681.x. http://dx.doi.org/10.1111/j.1540-6261.1992.tb04681.x.

Gartley, H.M. 1935. Profits in the stock market. Lambert-Gann Publishing, Pomeroy, Wash.

Granvillle, Joseph E. 1976. New strategy of daily stock market timing for maximum profit, Prentice-Hall, Inc.

Pavlov, Vlad, and Stan Hurn. 2012. "Testing the profitability of moving-average rules as a portfolio selection strategy." Pacific-Basin Finance Journal $20 \quad$ (5) (November): 825-842. doi:10.1016/j.pacfin.2012.04.003. http://linkinghub.elsevier.com/retrieve/pii/S0927538X12000327.

Sullivan, Ryan, Allan Timmermann, and Halbert White. 1999. "Data-snooping, technical trading rule performance, and the bootstrap." Journal of Finance 54 (5): 1647-1691. 